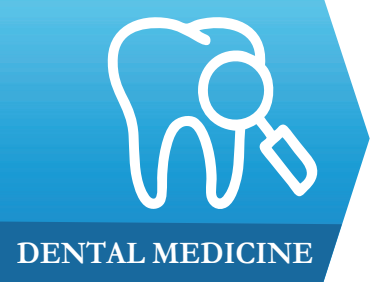

1) Public Health Dentistry Department, Rajasthan Dental College, India

2) Public Health Dentistry Department, Rajasthan Dental College and Hospital, India

3) Pedodontics Department, Vyas Dental College, India

4) Prosthodontics Department, NIIMS University, India

5) Public Health Dentistry Department, Pacific Dental College and Hospital, India

DOI: $10.15386 /$ cjmed-976

Manuscript received: 01.02.2018 Received in revised form: 24.04 .2018 Accepted: 10.05.2018

Address for correspondence: solankijitender@gmail.com

\title{
Attitude towards oral hygiene among different socio-economic groups in Jaipur city, Rajasthan
}

Priyanka Mishra ${ }^{1}$, Jitender Solanki ${ }^{2}$, Rahul Choudhary ${ }^{3}$, Chetan Sharma ${ }^{4}$, Prachi Sharma ${ }^{1}$, Disha Shah ${ }^{5}$

\begin{abstract}
Background. Socio-economic status is a total measure of a person's work experience and of an individual or family economic and social position in relation to others, based on income, education and occupation.

Objective. The study was conducted to determine the differences in attitudes of people from different socioeconomic statuses towards their oral hygiene.

Method. A cross sectional study was conducted among subjects of various socioeconomic groups. Socioeconomic status and oral hygiene data was collected using Aggarwal scale having 22 items questionnaire addressing various aspects of knowledge and attitude of subjects towards oral health, and simplified Oral Hygiene Index (OHI- S), respectively. Statistical analysis was done using chi- square test and frequency distribution $(\mathrm{P}<0.05$ taken as significant).

Results. Among 500 subjects, 260 (52\%) were found to have good oral hygiene, and most of them (43.46\%) were from lower middle class group. A highly significant association was found between the oral hygiene and socioeconomic status $(\mathrm{p}=0.000)$.

Conclusion. It could be concluded that the socioeconomic status is not the only factor that determines a person's attitude towards oral hygiene, but other factors such as lack of awareness, lack of availability of dentist nearby, fear and anxiety also play an important role.
\end{abstract}

Keywords: attitude, oral hygiene, socio-economic group, Aggarwal scale, oral hygiene index

\section{Introduction}

Oral health is an essential component of general health and wellbeing. A healthy mouth enables an individual to lead a healthy and diseasefree life [1].The mouth is considered to be a mirror of the body and the gateway to good health [2]. Oral diseases present a major public health problem worldwide [3]. About $90 \%$ of people worldwide, mostly adults, have experienced dental caries, and are most prevalent among Asian and Latin American countries [4]. This can be attributed to several factors, mental attitude of a person, mainly lack of oral health awareness, and consumption of refined forms of carbohydrates [5].

Inequalities in socioeconomic status represent one of the main reasons of health disparities [6]. Among the various determinants, social determinants are the most complex and challenging of all. It is concerned with various aspects of human life and the environment a person resides in [7]. There is a great difference in the prevalence or incidence of oral health of individuals with different socioeconomic status [8]. Throughout Europe, it has been found evident that people of low socioeconomic group suffer with a heavier burden of oral health problems than their better-off counterparts [9]. The term inequality has a moral and ethical dimension which refers to differences which are unnecessary and avoidable but, in addition, are also considered unfair and unjustified [9]. The population groups that suffer the worst oral health are mostly those who are below poverty line and which are illiterate or have basic education only. People with higher socioeconomic status afford better housing, better quality of life and good access to oral health care along with a high level of education which in turn increases the opportunity to engage in oral health-promoting behaviors. 
Differences in income and employment of parents generate inequalities among oral health status of children also [6].

According to Ottawa Charter for Health Promotion "health is created and lived by people within the settings of their everyday life; where they learn, work, play and love", which highlights the importance of healthy settings as an infrastructure for health production and maintenance, including schools, worksites, cities, local communities, and hospitals [10].

Studies conducted in this field confirm the link between socioeconomic status and oral health in an individual, and various factors which directly or indirectly affect the oral health [10-13].

Studying the literature and seeing the diversity present in the population of Jaipur city, the present study was undertaken with the aim to determine the differences in attitudes of people from different socioeconomic statuses towards their oral hygiene.

\section{Method}

The present cross sectional questionnaire-based study was carried out among residents of Jaipur city during April, 2016 to July, 2016 to determine the differences in attitudes of people from different socioeconomic statuses towards their oral hygiene.

The study was conducted among the people with different socioeconomic status residing in Jaipur city. Permission was obtained from the institute's ethical committee and informed verbal consent was obtained from the study participants.

Five hundred study subjects were randomly selected using convenient sampling method, based on the inclusion and the exclusion criteria.

Inclusion criteria:

- Over 21 years of age.

- Permanent residents of Jaipur city.

Exclusion criteria:

- Medically compromised subjects.

- Incompletely filled questionnaire.

- Not willing to participate in the study or those who were not cooperative.

The questionnaires were distributed to the subjects and later on collected after they were duly filled. The questionnaires comprised demographic details, oral hygiene methods and 22 questions which determined the socio economic status of the subject (Aggarwal scale 2013). The demographic details included name, age, sex, address, geographical location and school. Oral hygiene methods included the brushing habits and the socio- economic status was measured based on the points given to each option of questions mentioned in the questionnaire (more the score, higher the socio- economic status). The oral hygiene status was recorded using OHI-S index [12].

\section{Statistical analysis}

Statistical analysis was done using chi- square test and frequency distribution was applied to find out the association among different socio economic groups and their oral hygiene status $. \mathrm{P}<0.05$ was taken as significant. SPSS 20.0.0 version software was used for statistical analysis.

\section{Results}

The present cross sectional study was carried out among 500 people with different socio economic status in Jaipur city. Among them, 342 (68.4\%) were males and 158 $(31.6 \%)$ were females. Among them 355 (71\%) subjects were residing in the urban area, while 145 (29\%) were those residing in the rural area. Maximum of the study subjects (39.2\%) were of the age group of 21- 30 years and among socioeconomic status, maximum of the subjects $(45.4 \%)$ were in lower middle class.

Table I shows the association of the oral hygiene status among various socio economic variables. In relation to income, it was observed that 145 (29\%) study subjects were in the group of per capita income of 10,000-19,999 Indian Rupee (INR) and among them 90 (62.06\%) subjects had good oral hygiene and only $6(4.13 \%)$ had poor oral hygiene. In relation to education, it was found that 149 (29.8\%) subjects were professionally qualified and none of them had poor oral hygiene while $38(25.50 \%)$ had fair oral hygiene. In relation to occupation, it was found that 245 (49\%) subjects were working in private sectors or had their independent business employing 2-20 persons, and among them only $10(4.08 \%)$ were found to have poor oral hygiene while 145 were found to have good oral hygiene. All the above result were found to be statistically highly significant $(\mathrm{p}=0.000)$.

Table II depicts the oral hygiene status of study groups with different socio economic status. It was found that among 500 study subjects, 227 subjects belonged to lower middle class among which 113 (49.8\%) had good oral hygiene while $21(9.3 \%)$ had poor oral hygiene. Only $1(0.2 \%)$ subject belonged to upper high class who had poor oral hygiene. Among 155 study subjects who belonged to poor socioeconomic status, $112(72.3 \%)$ had good hygiene and only 3 $(1.9 \%)$ were found to have poor oral hygiene status. A highly significant association was found between the oral hygiene and socio economic status $(\mathrm{p}=0.000)$. 
Table I. Association between oral health status and socio economic variables (chi- square).

\begin{tabular}{|c|c|c|c|c|c|c|c|}
\hline \multirow{2}{*}{\multicolumn{2}{|c|}{ Oral hygiene index-simplified }} & \multicolumn{3}{|c|}{ Oral hygiene index-simplified } & \multirow[t]{2}{*}{ Total } & \multirow[t]{2}{*}{$x^{2}$} & \multirow[t]{2}{*}{ p value } \\
\hline & & Good & Fair & Poor & & & \\
\hline \multirow{7}{*}{$\begin{array}{l}\text { Income } \\
\text { (INR) }\end{array}$} & Less than 1,000 & 1 & 3 & 7 & 11 & 149.44 & \multirow{7}{*}{$* 0.00$} \\
\hline & $1,000-2,499$ & 1 & 20 & 11 & 32 & & \\
\hline & $2,500-4,999$ & 13 & 27 & 12 & 52 & & \\
\hline & $5,000-9,999$ & 35 & 50 & 16 & 101 & & \\
\hline & $10,000-19,999$ & 90 & 49 & 6 & 145 & & \\
\hline & $20,000-49,999$ & 91 & 33 & 1 & 125 & & \\
\hline & More than 50,000 & 29 & 4 & 1 & 34 & & \\
\hline \multirow{8}{*}{ Education } & Illiterate & 0 & 1 & 4 & 5 & 141.11 & \multirow{8}{*}{$* 0.00$} \\
\hline & Just literate but no schooling & 2 & 4 & 5 & 11 & & \\
\hline & Less than primary but attended school for at least one year & 1 & 3 & 2 & 6 & & \\
\hline & Primary pass but less the 10th class & 7 & 22 & 13 & 42 & & \\
\hline & 10th class pass but less than graduation & 12 & 30 & 15 & 57 & & \\
\hline & Graduation & 64 & 46 & 10 & 120 & & \\
\hline & Postgraduation (non- technical including Ph.D) & 63 & 42 & 5 & 110 & & \\
\hline & $\begin{array}{l}\text { Professional qualification with technical degrees or diplomas } \\
\text { (Doctors, Eng.,CA, MBA etc) }\end{array}$ & 111 & 38 & 0 & 149 & & \\
\hline \multirow{6}{*}{ Occupation } & None of the family member is employed & 0 & 0 & 1 & 1 & 105.07 & \multirow{6}{*}{$* 0.00$} \\
\hline & Self- employed with income less than 5000INR & 6 & 9 & 7 & 22 & & \\
\hline & $\begin{array}{l}\text { Self- employed (e.g. shops, Rehdies, or petty business with } \\
\text { income more than } 5000 \mathrm{INR} \text { ) }\end{array}$ & 4 & 17 & 7 & 28 & & \\
\hline & Service at shop, home, transport, own cultivation of land & 20 & 37 & 24 & 81 & & \\
\hline & $\begin{array}{l}\text { Service in private sector or independent business employing } \\
2-20 \text { persons }\end{array}$ & 145 & 90 & 10 & 245 & & \\
\hline & $\begin{array}{l}\text { Service in central/state/public undertaking or owner of a } \\
\text { company employing }>20 \text { persons/self- employed professionals }\end{array}$ & 85 & 33 & 5 & 123 & & \\
\hline
\end{tabular}

Table II. Distribution of oral hygiene status among different socio economic variables (chi- square).

\begin{tabular}{|c|c|c|c|c|c|c|}
\hline \multirow[t]{2}{*}{ Status } & \multicolumn{3}{|c|}{ Oral hygiene index-simplified } & \multirow[t]{2}{*}{ Total } & \multirow[t]{2}{*}{$\mathbf{x}^{2}$} & \multirow[t]{2}{*}{ p value } \\
\hline & Good & Fair & Poor & & & \\
\hline Very poor or below poverty line & 21 & 4 & 1 & 26 & \multirow{7}{*}{116.72} & \multirow{7}{*}{$* 0.00$} \\
\hline Poor & 112 & 40 & 3 & 155 & & \\
\hline Lower middle & 113 & 93 & 21 & 227 & & \\
\hline Upper middle & 12 & 40 & 19 & 71 & & \\
\hline High & 2 & 9 & 9 & 20 & & \\
\hline Upper high & 0 & 0 & 1 & 1 & & \\
\hline Total & 260 & 186 & 54 & 500 & & \\
\hline
\end{tabular}

*significant $\mathrm{p} \leq 0.05$

\section{Discussion}

The present study was conducted among the rural and urban population of Jaipur city of Rajasthan to evaluate the attitude of people with different socio economic status towards their oral hygiene.

Majority of the subjects (71\%) were from the urban area of Jaipur city. Regarding oral hygiene habits, $360(72 \%)$ subjects brushes their teeth once a day. This observation is found similar to that observed in western industrialized countries (58.3\%) [14,15] but observed high when compared with some industrialized countries of East Europe [14- 16]. This observation is contrary to the study conducted by Harikiran et al. [17] (38.5\%), and a study by Sahil handa et al. shows that almost every study subject brush their teeth [18] It was observed that only $28 \%$ of subjects brushed their teeth twice every day. Just by mass health education, brushing twice in a day cannot be implemented in the community [19]. The majority of the subjects $(87.8 \%)$ used tooth brush with tooth paste as oral hygiene aid. Similar results were reported by Sahil Handa et al. in Gurugram where $81 \%$ used both tooth brush and tooth paste [18], and Punitha Sivaprakasam (62.9\%), in Kanchipuram district [20]. This result is not in accordance with that of the study conducted by Mahesh Kumar et al. in Chennai, where the use of charcoal as a medium to brush their teeth prevails over the tooth brushes [21]. The reason could be probably a lack of awareness or affordability for tooth brush and tooth paste in this population.

As per the results obtained in this study, oral hygiene of the subjects is not only related to their 
socioeconomic status but also to other factors such as lack of awareness, availability of any nearby dentist, anxiety and inconvenience in transport. Maximum number of subjects (260) had good oral hygiene and not all of them belonged to lower socioeconomic status. Even subjects with higher socioeconomic status $(45 \%)$ were found to have poor oral hygiene. This finding is not in accordance with several studies conducted in various parts of the countries [22]. These findings show the neglect attitude of the people towards their own oral hygiene.

The study conducted in Brazil by Paula et al also found that school children who belonged to families whose income was lower than one minimum wage were 1.89 times more likely to have dental problems, as the home environment is an important social determinant of children's oral health [23].

\section{Conclusion}

In the present study a positive relation was observed among people with different socio economic status and their oral hygiene. Suitable oral health promotion, advancement policies and activities should be directed to the social, economic, and environmental causes of dental disease at the primary, secondary, and tertiary health care levels using strategies at macro and micro levels. In view of the recurrent theoretical discussions about health promotion and social determinants of health, the results of this study provide important data about the contribution of social determinants (such as their different conceptual levels) to periodontal experience, and for the planning of oral health promotion actions in public health.

\section{References}

1. Levine R, Stillman-Lowe C. The scientific basis of dental health education. Community Dent Health. 2002 Jun;19:127.

2. Grewal N, Kaur M. Status of oral health awareness in Indian children as compared to Western children: a thought provoking situation (a pilot study). J Indian Soc Pedod Prev Dent. 2007;25:15 19.

3. Petersen PE. The World Oral Health Report 2003: continuous improvement of oral health in the 21st century--the approach of the WHO Global Oral Health Programme. Community Dent Oral Epidemiol. 2003;31 Suppl 1:3-23.

4. Petersen PE, Bourgeois D, Ogawa H, Estupinan-Day S, Ndiaye C. The global burden of oral diseases and risks to oral health. Bull World Health Organ. 2005;83:661-669.

5. US General Accounting Offices. Oral Health: Dental Disease is a Chronic Problem among Low-Income Populations. Washington, DC: Report to Congressional Requesters; 2000.

6. Timiş T, Dănilă I. Socioeconomic status and oral health. The Journal of Preventive Medicine 2005;13:116-121.
7. Wilkinson R, Marmot M. Social determinants of health. The solid facts. WHO Regional Office for Europe, Copenhagen, 2003. 8. Locker D, Ford J. Using area-based measures of socioeconomic status in dental health services research. J Public Health Dent. 1996;56:69-75.

9. Whitehead M. The concepts and principles of equity in health. WHO Regional Office for Europe, 2000.

10. Daly B, Watt R, Batchelor P, Treasure E. Essential dental public health. Oxford University Press, 2002; pp 90-97.

11. Locker D. Deprivation and oral health: a review. Community Dent Oral Epidemiol. 2000;28:161-169.

12. Aggarwal OP, Bhasin SK, Sharma AK, Chhabra P, Aggarwal $\mathrm{K}$, Rajoura OP. A new instrument (scale) for measuring the socioeconomic status of a family: Preliminary study. Indian Journal of Community Medicine. 2005;30:111-114.

13. Singh V, Paliwal A, Mohan I, Bhardwaj SL, Choudhary RC, Sharma BN. The study of socioeconomic factor affecting breast feeding Practice among family of rural area of Jaipur. International Journal of Medical Science and Education 2014;1:30-38.

14. King A, World B, Tudor-Smith C, Harel Y. Dietary habits, dental care and body image. In: World Health Organisation. The Health of Youth: A Cross-National Survey. Copenhagen: WHO Regional Office for Europe 1995; pp 39-55.

15. Petersen PE, Danila I, Samoila A. Oral health behavior, knowledge, and attitudes of children, mothers, and schoolteachers in Romania in 1993. Acta Odontol Scand. 1995;53:363-368.

16. Chen MM, Andersen RM, Barmes DE, Leclercq MH, Lyttle CS. Comparing oral health care systems: A second international collaborative study. Geneva: WHO; 1997.

17. Harikiran AG, Pallavi SK, Hariprakash S, Ashutosh, Nagesh KS. Oral health-related KAP among 11- to 12-year-old school children in a government-aided missionary school of Bangalore city. Indian J Dent Res. 2008;19:236-242.

18. Handa S, Prasad S, Rajashekharappa CB, Garg A, Ryana HK, Khurana C. Oral Health Status of Rural and Urban Population of Gurgaon Block, Gurgaon District, Using WHO Assessment Form through Multistage Sampling Technique. J Clin Diagn Res. 2016;10:ZC43-ZC51.

19. Peng B, Petersen PE, Tai BJ, Yuan BY, Fan MW. Changes in oral health knowledge and behaviour 1987-95 among inhabitants of Wuhan City, PR China. Int Dent J. 1997;47:142-147.

20. Punitha VC, Sivaprakasam P. Oral hygiene status, knowledge, attitude and practice of oral health among rural children of Kanchipuram District. Indian J Multidiscip Dent. 2011;1:115-118. 21. Mahesh Kumar P, Joseph T, Varma RB, Jayanthi M. Oral health status of 5 years and 12 years school going children in Chennai city--an epidemiological study. J Indian Soc Pedod Prev Dent. 2005;23:17-22.

22. Bodhale P, Karkare S, Khedkar S. Knowledge and attitude of parents toward oral health maintenance and treatment modalities for their children. Journal of dental research and review 2014;1:24-27. 23. Paula JS, Ambrosano GM, Mialhe FL. The impact of social determinants on schoolchildren's oral health in Brazil. Braz Oral Res. 2015;29:1-9. 